\title{
A Novel Synthesis of Poly(germyl ether) by Regioselective Polyaddition of Dichlorogermane with Bisepoxide
}

\author{
Tadatomi Nishikubo, ${ }^{*}$ Atsushi KameYama, and Yasuhiro Kimura \\ Department of Applied Chemistry, Faculty of Engineering, Kanagawa University, \\ Rokkakubashi, Kanagawa-ku, Yokohama 221, Japan
}

(Received April 12, 1995)

\begin{abstract}
New polymers with germyl ether skeletons in the main chain were synthesized by a novel addition reaction of dichlorodimethylgermane (CMG) or dichlorodiphenylgermane (CPG) with bisphenol A diglycidyl ether (BPGE) using tetrabutylammonium bromide (TBAB) as a catalyst. The polyaddition of dichlorogermanes with BPGE proceeded very smoothly and regioselectively in the presence of $5 \mathrm{~mol} \%$ of TBAB at $90^{\circ} \mathrm{C}$ in a sealed tube to give the corresponding polymers 4 and 5 in high yields. On the other hand, no reaction occurred without the catalyst. The rate of polyaddition was affected by the reaction temperature, the nature of reaction solvent, the nature of catalyst, the catalyst concentration, and the monomer concentration. The poly(germyl ether)s are relatively stable in the solid state when allowed to stand in contact with the atmosphere; however, they decompose gradually in solution when in contact with water.

KEY WORDS Poly(germyl ether) / Regioselective Polyaddition

/ Dichlorodimethylgermane / Dichlorodiphenylgermane / Bisepoxide /
\end{abstract}

Polymers with silicon in the main chain have received much attention as high-performance materials. Poly(siloxane)s with low temperature flexibility and high temperature stability have been used widely as elastomers and plastics in various industries. These polymers have also been studied as useful materials for medical applications, photo-lithography and polymer-supports for liquid crystal compounds due to such characteristics as good transparency, oxygen-permeability, flexibility, and resistance to oxygen-reactive ion etching. Poly(silane)s have been of increasing interest as photo-resists, photo-conductors, semiconductors, and nonlinear optical materials, since they exhibit excellent physical properties due to the $\sigma$ conjugated bond.

Recently, polymers containing germanium in the main chain, which is in the 14 column as is silicon, have also been of interest as new functional materials ${ }^{1-4}$ in the field of elec- tronics and opto-electronics. Carraher and Dammeier have reported ${ }^{5}$ first synthesis of poly(ester)s having germanium in the main chain by the interfacial reaction of organogermanium dichlorides with sodium dicarboxylates. Trefonas and $\mathrm{West}^{6}$ have synthesized a soluble poly(germane) by Wurtz-type polycondensation of dibutyldichlorogermane in toluene. Tanaka et al. ${ }^{7}$ synthesized certain germanium-containing polymers by the polycondensation of $p$-bis(chloromethylphenylgermyl)benzene and similar germanium compounds with sodium metal. Zhou et al. ${ }^{8}$ reported the anionic ring-opening polymerization of 1-germa-1,1-dimethyl[3,4,c]thienocyclopentane to give a polymer containing germanium in the main chain. However, there is no other report for the synthesis of germanium-containing polymers by the addition reaction, although Kobayashi et al. ${ }^{9}$ reported recently the synthesis of certain new ger-

\footnotetext{
* To whom all correspondence should be addressed.
} 
manium-containing polymers by the polyadditions of germylene with $p$-benzoquinones, cyclic $\alpha, \beta$-unsaturated ketones, and acetylene monomers.

Meanwhile, the authors reported ${ }^{10}$ recently that polyaddition of bisepoxides with diacyl chlorides proceed very smoothly and regioselectively using quaternary onium salts or crown ether complexes as catalysts to give the corresponding poly(ester)s. Poly(silyl ether)s ${ }^{11}$ with high molecular weights were also synthesized by the regioselective polyaddition of bisepoxides with dichlorosilanes.

This new reaction system seems to be applied widely to the synthesis of other new polymers containing 14 elements in the main chain. In this paper, the authors report a novel synthesis of poly(germyl ether)s by the regioselective polyaddition of dichlorogermanes with bisepoxide using a quaternary onium salt as the catalyst.

\section{EXPERIMENTAL}

\section{Materials}

Organic solvents were dried using $\mathrm{P}_{2} \mathrm{O}_{5}$, $\mathrm{CaH}_{2}$, or $\mathrm{Na}$ metal wire and purified in the usual way before use. Commercial deuterated solvents were used without further purification. Reagent grade dichlorodimethylgermane (CMG) and dichlorodiphenylgermane (CPG) were used without further purification. Phenyl glycidyl ether (PGE) was purified twice by distillation under reduced pressure. Bisphenol A diglycidyl ether (BPGE) was recrystallized four times from the mixed solvent of methanol and methyl ethyl ketone $(4: 1, \mathrm{v} / \mathrm{v})$. Tetrabutylammonium bromide (TBAB) and triphenylphosphine (TPP) were purified by recrystallization from ethyl acetate and methanol, respectively.

\section{Measurement}

Infrared (IR) spectra were measured on a JASCO model IR-700 spectrometer. The ${ }^{1} \mathrm{H}$ NMR spectra were recorded on JEOL model
JNM FX-200 $(200 \mathrm{MHz})$ instrument in the deuterated solvents using $\mathrm{Me}_{4} \mathrm{Si}$ (TMS) as an internal standard. The purification and isolation of the product formed from CPG with PGE were carried out using a recycling preparative HPLC (Japan Analytical Industry Co., Ltd.; model LC-908) connected in series with JAIGEL-1H and JAIGEL-2H columns using chloroform as the eluent. The molecular weights of the polymers were estimated by gel permeation chromatography (GPC) with the use of a model LC-909 GPC (Japan Analytical Industry Co., Ltd.) equipped with a refractive index detector using JAIGEL1HA-F and JAIGEL-1H-A gel columns (eluent: tetrahydrofuran (THF), calibrated with narrow molecular weight polystyrene standards).

\section{Addition Reaction of CMG with PGE in Toluene- $d_{8}$}

CMG (0.0694 g; $0.4 \mathrm{mmol})$, PGE (0.1202 g; $0.8 \mathrm{mmol})$, TBAB $(0.0129 \mathrm{~g} ; 0.04 \mathrm{mmol})$ as a catalyst, and toluene- $d_{8}(0.4 \mathrm{ml})$ as a reaction solvent were all charged into a NMR glass tube in a dry box, after which the tube was evacuated, then sealed using a gas torch. The addition reaction of $\mathrm{CMG}$ with $\mathrm{PGE}$ was conducted at $90^{\circ} \mathrm{C}$ in the sealed tube for $24 \mathrm{~h}$, and then the ${ }^{1} \mathrm{H}$ NMR spectrum of reaction product 1 was measured as follows: $\delta 0.455$, 0.508 , and $0.557\left(\mathrm{~s}, 6 \mathrm{H}, \mathrm{Ge}-\mathrm{CH}_{3}\right), 3.37-3.59$ $\left(\mathrm{m}, 4 \mathrm{H}, \mathrm{CH}_{2} \mathrm{Cl}\right), 3.71-3.90\left(\mathrm{~m}, 4 \mathrm{H}, \mathrm{O}-\mathrm{CH}_{2}\right)$, $4.08-4.22(\mathrm{~m}, 2 \mathrm{H}, \mathrm{O}-\mathrm{CH}), 6.48-7.28 \mathrm{ppm}$ ( $\mathrm{m}, 10 \mathrm{H}$, aromatic protons).

\section{Addition Reaction of CPG with PGE in toluene- $d_{8}$}

CPG $(0.1191 \mathrm{~g} ; 0.4 \mathrm{mmol})$ was allowed to react with PGE $(0.1202 \mathrm{~g} ; 0.8 \mathrm{mmol})$ in the presence of TBAB $(0.0129 \mathrm{~g} ; 0.04 \mathrm{mmol})$ in toluene- $d_{8}(0.4 \mathrm{ml})$ under the same conditions. The ${ }^{1} \mathrm{H}$ NMR spectrum of reaction product 2 was as follows: $\delta 3.35-3.66\left(\mathrm{~m}, 4 \mathrm{H}, \mathrm{CH}_{2} \mathrm{Cl}\right)$, $3.87\left(\mathrm{dd}, J=2.44 \mathrm{~Hz}, J=5.37 \mathrm{~Hz}, 2 \mathrm{H}, \mathrm{O}-\mathrm{CH}_{2}\right)$, $3.93\left(\mathrm{dd}, J=2.93 \mathrm{~Hz}, J=5.37 \mathrm{~Hz}, 2 \mathrm{H}, \mathrm{O}-\mathrm{CH}_{2}\right.$ ), 
$4.27-4.52(\mathrm{~m}, 2 \mathrm{H}, \mathrm{O}-\mathrm{CH}), 6.56-6.87(\mathrm{~m}, 6 \mathrm{H}$, aromatic protons), $6.97-7.28(\mathrm{~m}, 10 \mathrm{H}$, aromatic protons), $7.59-7.93 \mathrm{ppm}(\mathrm{m}, 4 \mathrm{H}$, aromatic protons).

\section{Attempted Purification and Isolation of Reaction \\ Product 2 of CPG with PGE}

The addition reaction of CPG with PGE was similarly carried out for 3 days, and then the reaction solvent was evaporated in vacuo. IR (neat): $1494\left(v_{\text {aromatic } C}=\mathrm{C}\right), 1243\left(v_{\mathrm{C}-\mathrm{o}}\right), 753$ $\mathrm{cm}^{-1}\left(v_{\mathrm{C}-\mathrm{Cl}}\right)$.

The reaction product 2 was washed with a small amount of water to remove the catalyst TBAB. The purification of adduct 2 which has a very high boiling point was conducted using the recycling preparative HPLC, and two products, $\mathbf{3 a}$ and $\mathbf{3 b}$, were isolated.

Yield of 3a: $0.114 \mathrm{~g}(76 \%$; estimated as 1chloro-2-hydroxy-3-phenoxypropane). IR (neat): $3284\left(v_{\mathrm{O}-\mathrm{H}}\right), 1508\left(v_{\text {aromatic }} \mathrm{C}=\mathrm{C}\right), 1247$ $\left(v_{\mathrm{C}-\mathrm{o}}\right), 753 \mathrm{~cm}^{-1}\left(v_{\mathrm{C}-\mathrm{Cl}}\right) .{ }^{1} \mathrm{H}$ NMR $(200 \mathrm{MHz}$, $\mathrm{CDCl}_{3}$, TMS): $\delta 2.65(\mathrm{~d}, J=5.86 \mathrm{~Hz}, 1 \mathrm{H}, \mathrm{OH})$, $3.63-3.82\left(\mathrm{~m}, 2 \mathrm{H}, \mathrm{CH}_{2} \mathrm{Cl}\right), 4.03-4.26(\mathrm{~m}, 3 \mathrm{H}$, $\mathrm{O}-\mathrm{CH}_{2}$ and $\left.\mathrm{O}-\mathrm{CH}\right), 6.86-7.40 \mathrm{ppm}(\mathrm{m}, 5 \mathrm{H}$, aromatic protons).

Yield of 3b: $0.041 \mathrm{~g}$. IR (neat): $3284\left(v_{\mathrm{O}-\mathrm{H}}\right)$, $1508 \mathrm{~cm}^{-1}\left(v_{\text {aromatic }} \mathrm{C}=\mathrm{C}\right) .{ }^{1} \mathrm{H}$ NMR $(200 \mathrm{MHz}$, $\left.\mathrm{CDCl}_{3}, \mathrm{TMS}\right): \delta 1.56(\mathrm{~s}, 0.6 \mathrm{H}, \mathrm{OH}), 7.18$ $7.68 \mathrm{ppm}(\mathrm{m}, 10 \mathrm{H}$, aromatic protons).

\section{Synthesis of Poly(germyl ether) (4) by the Reaction of CMG with BPGE}

A typical procedure for the polyaddition of CMG with BPGE to produce poly(germyl ether) 4 was as follows: CMG $(0.0694 \mathrm{~g}$, $0.4 \mathrm{mmol})$, BPGE $(0.1362 \mathrm{~g}, 0.4 \mathrm{mmol}), \mathrm{TBAB}$ $(0.0129 \mathrm{~g}, 0.04 \mathrm{mmol})$, and toluene $(0.4 \mathrm{ml})$ were charged into a glass tube in a dry box, and then the tube was sealed as explained above. The reaction was carried out at $90^{\circ} \mathrm{C}$ in the sealed tube for 3 days, then the solution was poured into dried $n$-hexane to precipitate the polymer. The recovered polymer was reprecipitated from the dried THF into the dried $n$-hexane, and dried at room temperature in vacuo. The yield of poly(germyl ether) 4 was $0.165 \mathrm{~g}(80 \%)$. The number average molecular weight $\left(M_{n}\right)$ of the polymer measured by GPC was $1800\left(M_{w} / M_{n}=1.82\right)$. IR (film): 1510 $\left(v_{\text {aromatic }} \mathrm{C}=\mathrm{C}\right), 1248\left(v_{\mathrm{C}-\mathrm{O}}\right), 750 \mathrm{~cm}^{-1}\left(v_{\mathrm{C}-\mathrm{Cl}}\right)$. ${ }^{1} \mathrm{H}$ NMR (toluene- $d_{8}$ ): $\delta 0.489,0.543$, and $0.592\left(\mathrm{~s}, 6 \mathrm{H}, \mathrm{Ge}-\mathrm{CH}_{3}\right), 1.58\left(\mathrm{~s}, 6 \mathrm{H}, \mathrm{C}-\mathrm{CH}_{3}\right)$, $3.32-3.57\left(\mathrm{~m}, 4 \mathrm{H}, \mathrm{CH}_{2} \mathrm{Cl}\right), 3.72-3.95(\mathrm{~m}, 4 \mathrm{H}$, $\left.\mathrm{O}-\mathrm{CH}_{2}\right), 4.10-4.32(\mathrm{~m}, 2 \mathrm{H}, \mathrm{O}-\mathrm{CH}), 6.08(\mathrm{~d}$, $J=9.01 \mathrm{~Hz}, 4 \mathrm{H}$, aromatic protons), 7.14 ppm (d, $J=9.01 \mathrm{~Hz}, 4 \mathrm{H}$, aromatic protons).

\section{Measurement of the Rate of Reaction of CMG with BPGE}

CMG (0.0694 g, 0.4 mmol), BPGE (0.1362 g, $0.4 \mathrm{mmol})$, TBAB $(0.0129 \mathrm{~g}, 0.04 \mathrm{mmol})$, and toluene- $d_{8}(0.4 \mathrm{ml})$ were charged into a NMR tube in the dry box, and then the tube was sealed as above. The reaction was carried out at $90^{\circ} \mathrm{C}$ in the sealed tube, and periodically analyzed by ${ }^{1} \mathrm{H}$ NMR to determine the degree of conversion of BPGE and the number average molecular weight $\left(M_{n}\right)$ of the produced polymer.

\section{Synthesis of Poly(germyl ether) (5) by the Reaction of $C P G$ with $B P G E$}

CPG $(0.1191 \mathrm{~g}, 0.4 \mathrm{mmol})$ was allowed to react with BPGE $(0.1362 \mathrm{~g}, 0.4 \mathrm{mmol})$ in the presence of TBAB $(0.0129 \mathrm{~g}, 0.04 \mathrm{mmol})$ in toluene $(0.4 \mathrm{ml})$ under the same conditions for the synthesis of polymer 4. The yield of poly(germyl ether) 5 was $0.226 \mathrm{~g}(89 \%)$. The $M_{n}$ of the polymer measured by GPC was 8000 $\left(M_{w} / M_{n}=1.52\right)$. IR (film): $1508\left(v_{\text {aromatic C }=\mathrm{C}}\right)$, $1246\left(v_{\mathrm{C}-\mathrm{o}}\right), 737 \mathrm{~cm}^{-1}\left(v_{\mathrm{C}-\mathrm{Cl}}\right) .{ }^{1} \mathrm{H}$ NMR (in toluene- $\left.d_{8}\right): \delta 1.56\left(\mathrm{~s}, 6 \mathrm{H}, \mathrm{CH}_{3}\right), 3.43-3.69(\mathrm{~m}$, $\left.4 \mathrm{H}, \mathrm{CH}_{2} \mathrm{Cl}\right), 3.79-4.21\left(\mathrm{~m}, 4 \mathrm{H}, \mathrm{O}-\mathrm{CH}_{2}\right)$, $4.28-4.56(\mathrm{~m}, 2 \mathrm{H}, \mathrm{O}-\mathrm{CH}), 6.52-6.79(\mathrm{~m}$, $6 \mathrm{H}$, aromatic protons), $6.92-7.26(\mathrm{~m}, 10 \mathrm{H}$, aromatic protons), $7.62-7.95 \mathrm{ppm}(\mathrm{m}, 4 \mathrm{H}$, aromatic protons).

\section{RESULTS AND DISCUSSION}

The addition reaction of CMG with PGE 


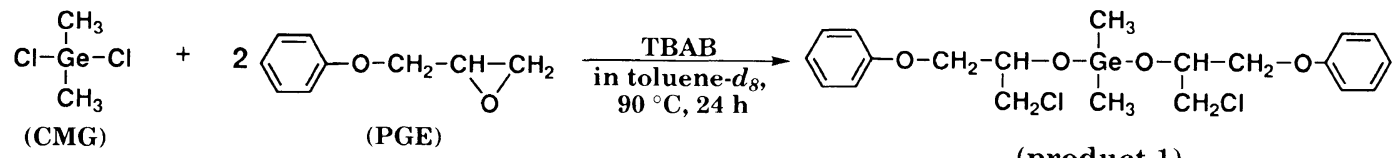

Scheme 1.

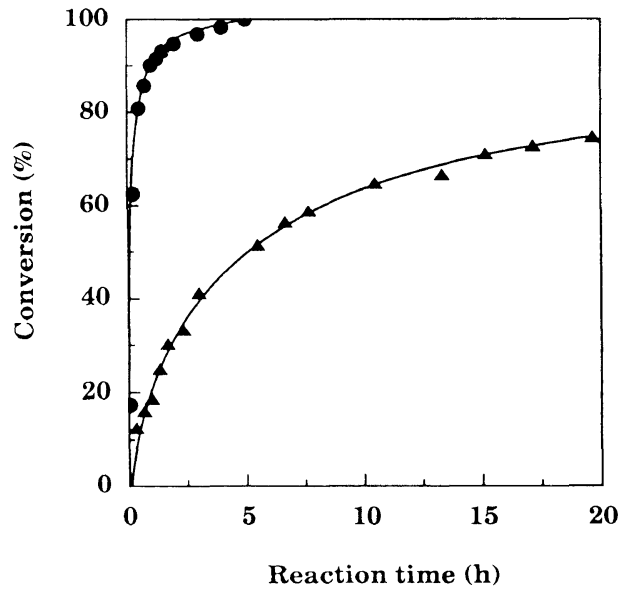

Figure 1. Effect of the temperature on the reaction of CMG $(0.4 \mathrm{mmol})$ with PGE $(0.8 \mathrm{mmol})$ using TBAB $(0.04 \mathrm{mmol})$ in toluene- $d_{8}(0.4 \mathrm{ml}):(\boldsymbol{\Delta})$ at room temperature; (○) at $90^{\circ} \mathrm{C}$.

was performed as a model reaction for the polyaddition of CMG with bisepoxide BPGE. The reaction was carried out using $5 \mathrm{~mol} \%$ of TBAB as a catalyst in toluene- $d_{8}$ at $90^{\circ} \mathrm{C}$ in the sealed tube for $24 \mathrm{~h}$, and the expected structure of reaction product 1 was confirmed by ${ }^{1} \mathrm{H}$ NMR. This result means that the addition reaction of $\mathrm{CMG}$ with $\mathrm{PGE}$ proceeded quantitatively and regioselectively without any side reaction to produce the corresponding product 1 (Scheme 1).

The degree of conversion of the reaction of CMG with PGE could be periodically analyzed by the change of the ${ }^{1} \mathrm{H}$ NMR spectrum. As shown in Figure 1, the reaction of CMG with PGE proceeded quantitatively at $90^{\circ} \mathrm{C}$ for $5 \mathrm{~h}$. The reaction proceeds even at room temperature using $5 \mathrm{~mol} \%$ of TBAB as the catalyst.

The rate of the reaction of CMG with PGE was affected by the nature of reaction solvent.

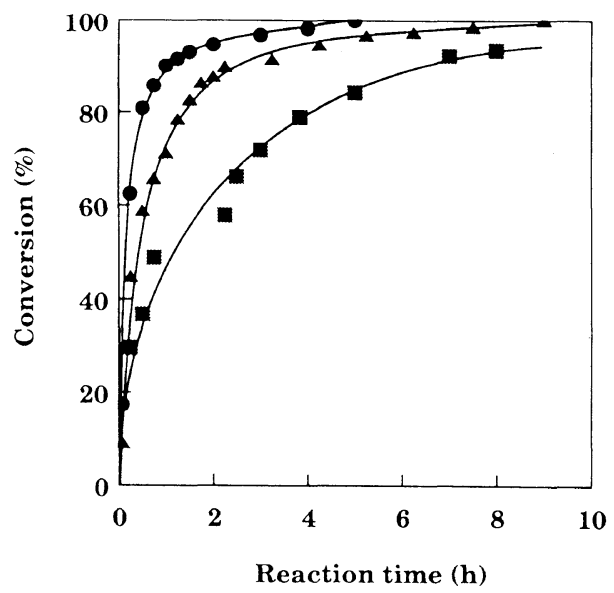

Figure 2. Effect of the solvent on the reaction of $\mathrm{CMG}$ $(0.4 \mathrm{mmol})$ with PGE $(0.8 \mathrm{mmol})$ using TBAB $(0.04 \mathrm{mmol})$ in the solvent $(0.4 \mathrm{ml})$ at $90^{\circ} \mathrm{C}:(\boldsymbol{\square})$ in $\mathrm{CDCl}_{3} ;(\boldsymbol{\Delta})$ in $\mathrm{CD}_{3} \mathrm{CN}$; $(\mathrm{O})$ in toluene- $d_{8}$.

As shown in Figure 2, the reaction proceeded at the highest rate in toluene- $d_{8}$, and the reaction in $\mathrm{CD}_{3} \mathrm{CN}$ was faster than in $\mathrm{CDCl}_{3}$.

The addition reaction of $\mathrm{CPG}$ with $\mathrm{PGE}$, which is a model reaction of CPG with BPGE, was conducted in the sealed NMR tube under the same reaction conditions, and it was confirmed by ${ }^{1} \mathrm{H}$ NMR spectrum that the reaction occurred quantitatively and regioselectively to form the corresponding product 2 . The purification and the isolation of reaction product $\mathbf{2}$ was attempted by washing with water followed by the recycling preparative HPLC, because reaction product 2 was a colorless syrup with a very high boiling point, and thus could not be isolated by distillation or by recrystallization. However, two other products, $\mathbf{3 a}$ and $\mathbf{3 b}$, were finally isolated. From IR and ${ }^{1} \mathrm{H}$ NMR spectra, 3a was determined to be 1-chloro-2-hydroxy-3- 
<smiles>ClC(Cl)(c1ccccc1)c1ccccc1</smiles>

(CPG)<smiles></smiles>

(PGE)<smiles>ClCC(COc1ccccc1)OC(OC(CCl)COc1ccccc1)(c1ccccc1)c1ccccc1</smiles>

(product 2)<smiles>OC(CCl)COc1ccccc1</smiles>

(product $3 \mathbf{a})$

(product $3 b)$

Scheme 2.

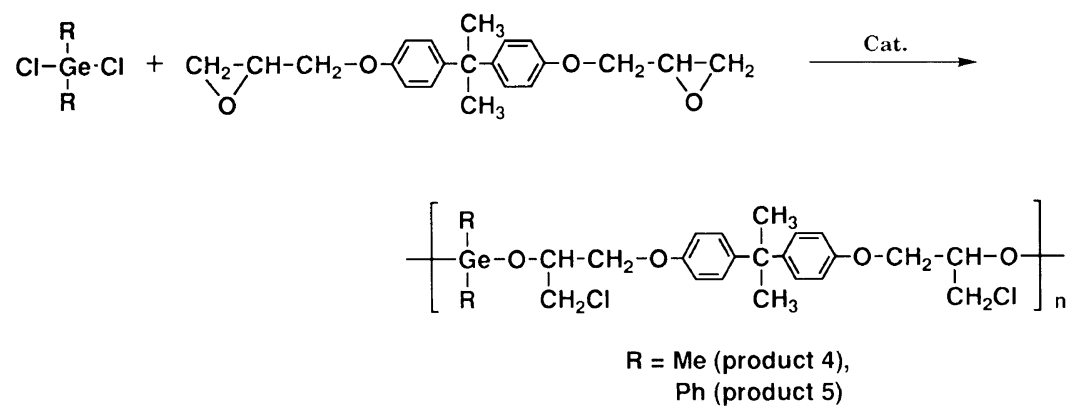

Scheme 3.

Table I. Polyaddition of dichlorogermanes with BPGE $^{a}$

\begin{tabular}{|c|c|c|c|c|c|}
\hline \multirow{2}{*}{$\begin{array}{l}\text { Run } \\
\text { no. }\end{array}$} & \multirow{2}{*}{ Dichlorogermane } & \multirow{2}{*}{$\frac{\text { Time }}{\text { day }}$} & \multirow{2}{*}{$\frac{\text { Yield }}{\%}$} & \multirow{2}{*}{$\begin{array}{c}M_{n}{ }^{\mathrm{b}} \\
\times 10^{-4}\end{array}$} & \multirow{2}{*}{$M_{w} / M_{n}^{\mathrm{b}}$} \\
\hline & & & & & \\
\hline 1 & CMG & 3 & 80 & 0.18 & 1.82 \\
\hline 2 & $\mathrm{CPG}$ & 3 & 89 & 0.80 & 1.52 \\
\hline 3 & $\mathrm{CPG}$ & 7 & 91 & 0.76 & 1.55 \\
\hline
\end{tabular}

a The reactions were carried out with $0.4 \mathrm{mmol}$ of dichlorogermane and $0.4 \mathrm{mmol}$ of BPGE in toluene $(0.4 \mathrm{ml})$ using TBAB $(0.04 \mathrm{mmol})$ as the catalyst at $90^{\circ} \mathrm{C}$ in the sealed tube. ${ }^{b}$ Estimated by GPC based on polystyrene standards.

phenoxypropane, and $\mathbf{3 b}$ was judged to be a mixture of poly(diphenylgermoxane)s as shown in Scheme 2 below. This result suggests that adduct $\mathbf{2}$ is unstable in water, and decomposes to produce the two hydrolysis products 3a and 3b due to the contact with water during the treatment and the recycling in the
Table II. Decomposition of poly(germyl ether) 5

\begin{tabular}{ccc}
\hline Time & $M_{n}{ }^{\mathrm{a}} \times 10^{-4}$ & $M_{w} / M_{n}{ }^{\mathrm{a}}$ \\
\hline $\mathrm{h}$ & & \\
\hline 0 & 0.80 & 1.52 \\
1 & 0.51 & 1.60 \\
2 & 0.43 & 1.59 \\
3 & 0.38 & 1.57 \\
\hline
\end{tabular}

a Estimated by GPC based on polystyrene standards at $40^{\circ} \mathrm{C}$.

HPLC column.

As summarized in Table I, poly(germyl ether)s (5) with $M_{n}=8000$ and 7600 were synthesized with 89 and $91 \%$ yields by the reaction of CPG with BPGE for 3 and 7 days using $5 \mathrm{~mol} \%$ of $\mathrm{TBAB}$ as the catalyst in toluene at $90^{\circ} \mathrm{C}$ in the sealed tube, respectively. Whereas, poly(germyl ether) (4) with $M_{n}=1800$ was obtained with $80 \%$ yield, when the reaction of CMG with BPGE was performed for 3 days 
under the same conditions (Scheme 3).

Resulting poly(germyl ether)s 4 and 5 were relatively stable in the solid state, although the stability of these polymers in the presence of moisture was obviously lower than that of poly(silyl ether)s prepared by the polyaddition of dichlorosilanes with bisepoxides. As summarized in Table II, the $M_{n}$ of polymer 5 dissolved in THF decreased with time. The same phenomenon was also found in the THF solution of polymer 4 . These results suggest that polymers $\mathbf{4}$ and $\mathbf{5}$ might be decomposed gradually by contact with water in solution as was adduct 2. Furthermore, it seems that polymer 4 with smaller substituents on the germyl moiety than polymer $\mathbf{5}$ decomposed
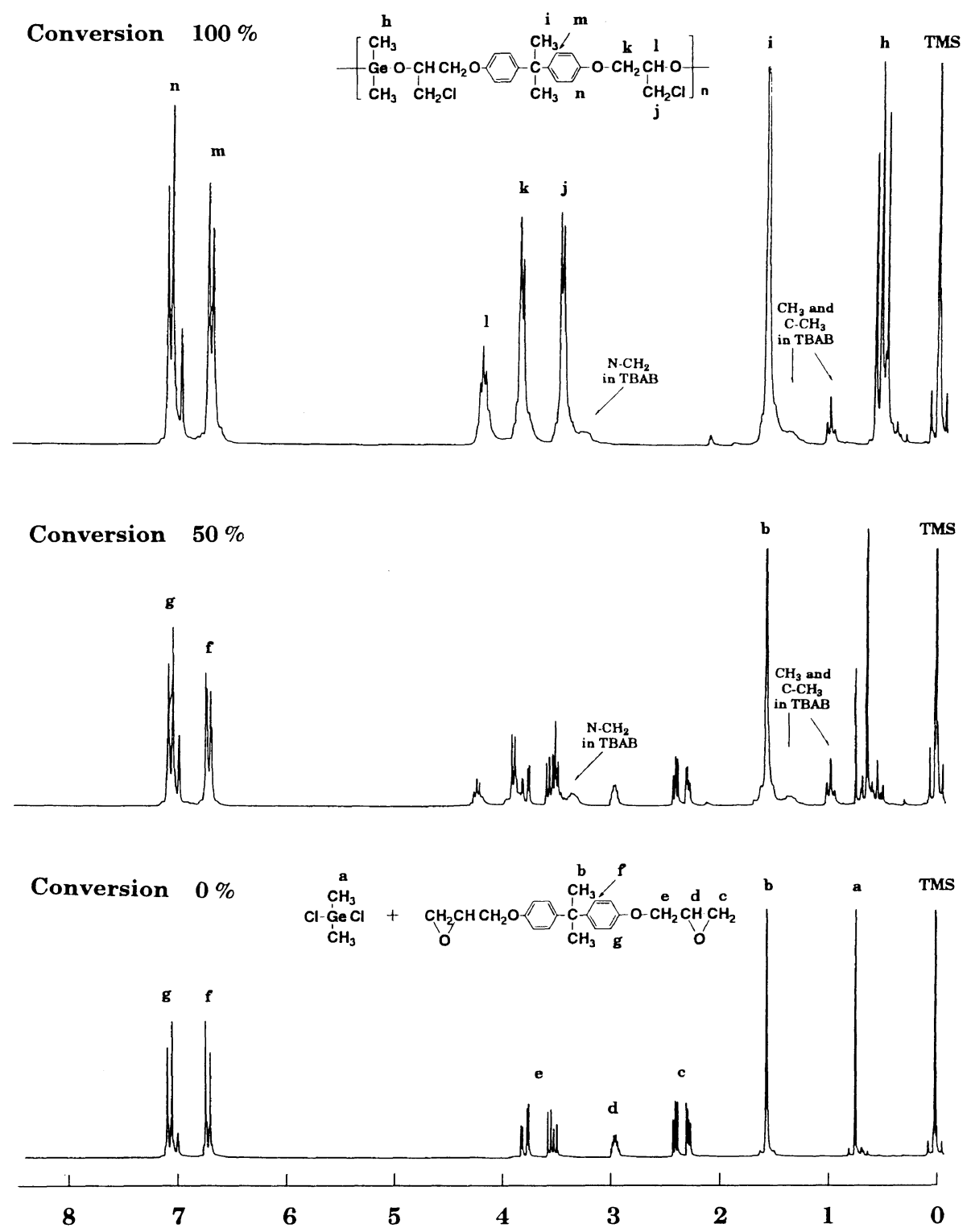

Figure 3. ${ }^{1} \mathrm{H}$ NMR spectra of poly(germyl ether) (4) formed by the polyaddition of CMG with BPGE in toluene- $d_{8}(200 \mathrm{MHz})$. 
during isolation of the polymer and measurement of the molecular weight by GPC, and disappointingly polymer 4 showed a lower molecular weight than polymer $\mathbf{5}$. That is, the introduction of a bulky and hydrophobic substituent on the germyl moiety in the main chain might stabilize the germyl ether linkage. Kobayashi and his co-workers ${ }^{9}$ have synthesized some hydrolytically stable poly(germyl ether)s by the polyaddition of bis[bis(trimethylsilyl)amido]-germanium(II) with benzoquinone derivatives.

As shown in Figure 3, the ${ }^{1} \mathrm{H}$ NMR spectra of the mixture of CMG with BPGE in toluene- $d_{8}$ exhibited the signals at 2.27 and $2.39 \mathrm{ppm}$ due to the methylene and at $3.95 \mathrm{ppm}$ due to the methine of the epoxy ring. These proton signals decreased as the reaction proceeded, and then new proton signals appeared at $3.32-3.57 \mathrm{ppm}$ due to the pendant $\mathrm{CH}_{2} \mathrm{Cl}$, at $3.72-3.95 \mathrm{ppm}$ due to the $\mathrm{CH}_{2} \mathrm{O}$ and at $4.14-4.32 \mathrm{ppm}$ due to the $\mathrm{CH}-\mathrm{O}$ of the main chain of poly(germyl ether) (4), when the reaction was performed using $5 \mathrm{~mol} \%$ of TBAB as the catalyst at $90^{\circ} \mathrm{C}$ in a sealed tube. This result suggests that the polyaddition of $\mathrm{CMG}$ with BPGE occurred regioselectively without any side reaction in the sealed tube. Accordingly, the degree of conversion of BPGE and the number average molecular weight $\left(M_{n}\right)$ of the produced polymer 4 can be determined by the ${ }^{1} \mathrm{H}$ NMR spectrum.

The effect of the reaction temperature was examined in toluene- $d_{8}$ solution, in which $5 \mathrm{~mol} \%$ of TBAB was used as the catalyst. As shown in Figure 4, the reaction of CMG with BPGE proceeded smoothly at both 60 and $90^{\circ} \mathrm{C}$, but it was found that the rate of polyaddition was enhanced by heating.

The catalyst activity of the polyaddition in toluene- $d_{8}$ at $90^{\circ} \mathrm{C}$ was evaluated. As shown in Figure 5, although the reaction of CMG with BPGE proceeded very smoothly using TBAB as a catalyst, the rate of the reaction was low using TPP as a catalyst. Meanwhile, no reaction of CMG with BPGE could be observed

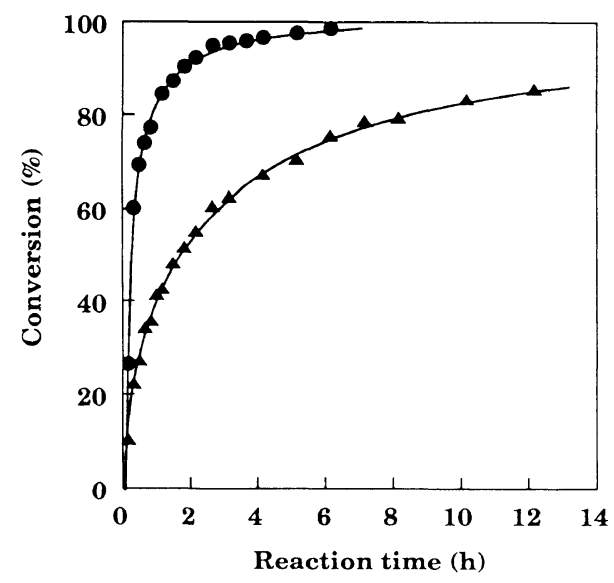

Figure 4. Effect of the temperature on the polyaddition of CMG $(0.4 \mathrm{mmol})$ with BPGE $(0.4 \mathrm{mmol})$ using TBAB $(0.04 \mathrm{mmol})$ in toluene- $d_{8}$ at various temperature: $(\boldsymbol{A})$ at $60^{\circ} \mathrm{C} ;(-)$ at $90^{\circ} \mathrm{C}$.

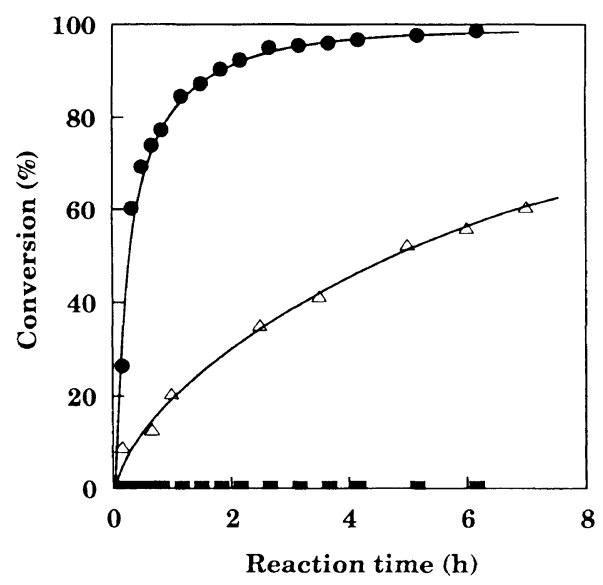

Figure 5. Effect of the catalyst on the polyaddition of CMG $(0.4 \mathrm{mmol})$ with BPGE $(0.4 \mathrm{mmol})$ in toluene- $d_{8}$ at

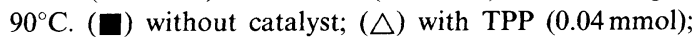
(O) with TBAB $(0.04 \mathrm{mmol})$.

without the catalyst under the same conditions.

The polyaddition of CMG with BPGE was examined in various deuterated organic solvents using $5 \mathrm{~mol} \%$ of TBAB as the catalyst at $90^{\circ} \mathrm{C}$. As suggested in Figure 6, the rates of polyaddition of CMG with BPGE in aromatic solvents such as toluene- $d_{8}$ and nitrobenzene- $d_{5}$ were higher than those of the polyaddition in $\mathrm{CDCl}_{3}$ and $\mathrm{CD}_{3} \mathrm{CN}$. The rate 


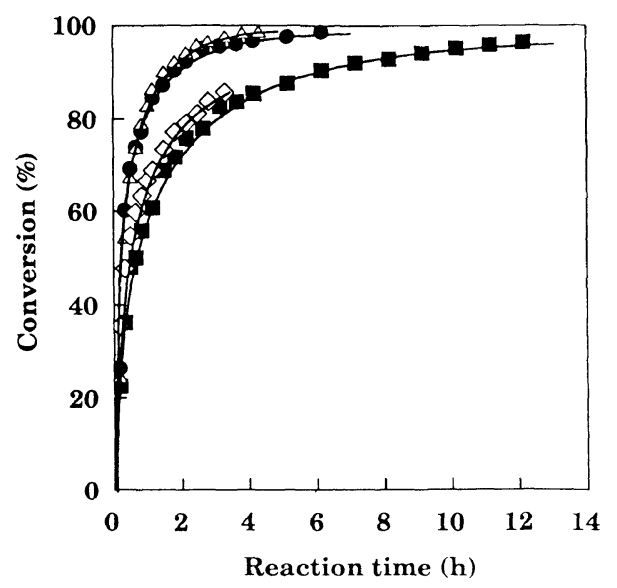

Figure 6. Effect of the solvent $(0.4 \mathrm{ml})$ on the polyaddition of CMG $(0.4 \mathrm{mmol})$ with BPGE $(0.4 \mathrm{mmol})$ using $\mathrm{TBAB}(0.04 \mathrm{mmol})$ at $90^{\circ} \mathrm{C}:(\square)$ in $\mathrm{CDCl}_{3} ;(\diamond)$ in $\mathrm{CD}_{3} \mathrm{CN}$; (๑) in toluene- $d_{8} ;(\triangle)$ nitrobenzene- $d_{5}$.

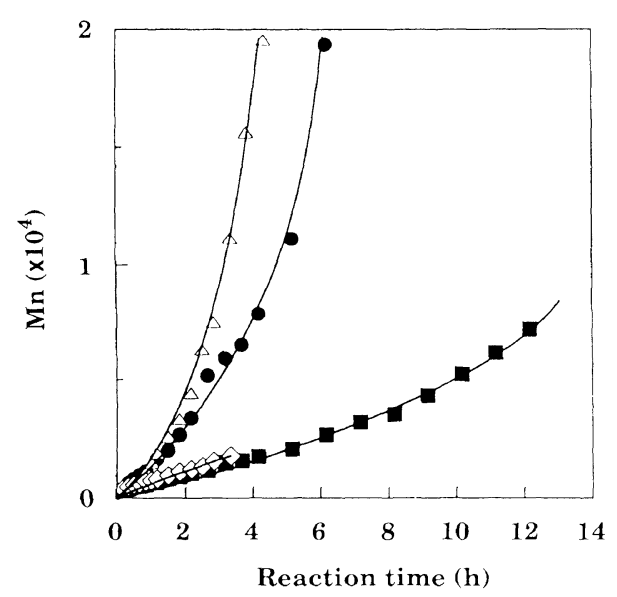

Figure 7. Correlation between the $\mathrm{Mn}$ and the time in the polyaddition of $\mathrm{CMG}(0.4 \mathrm{mmol})$ with $\mathrm{BPGE}$ $(0.4 \mathrm{mmol})$ using TBAB $(0.04 \mathrm{mmol})$ in the solvent $(0.4 \mathrm{ml})$ at $90^{\circ} \mathrm{C}:(\square)$ in $\mathrm{CDCl}_{3} ;(\diamond)$ in $\mathrm{CD}_{3} \mathrm{CN} ;(\bigcirc)$ in toluene- $d_{8}$; $(\triangle)$ nitrobenzene- $d_{5}$.

of increase in the number average molecular weights $\left(M_{n}\right)$ of poly(germyl ether) 4 was also affected by the nature of the reaction solvent, and polymer 4 with higher molecular weight was obtained in nitrobenzene- $d_{5}$ under the same conditions (Figure 7). These results mean that high polar aromatic solvents are suitable reaction solvents for the polyaddition of di-



Figure 8. Correlation between the $\mathrm{Mn}$ and the conversion in the polyaddition of CMG $(0.4 \mathrm{mmol})$ with BPGE $(0.4 \mathrm{mmol})$ using TBAB $(0.04 \mathrm{mmol})$ in toluene- $d_{8}$ at $90^{\circ} \mathrm{C}$.

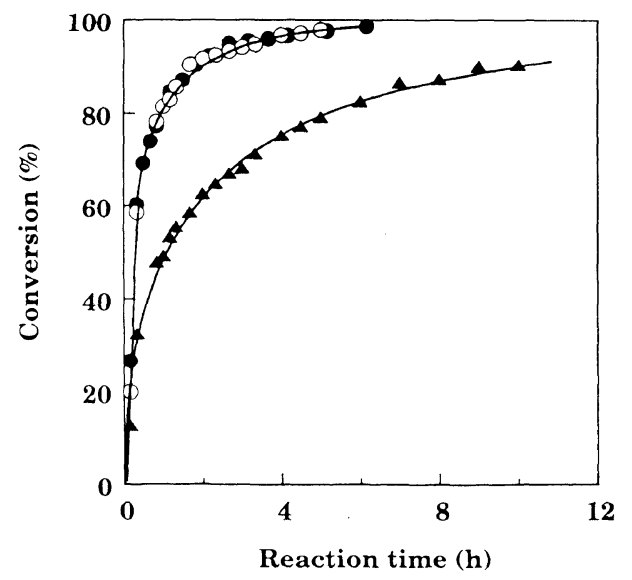

Figure 9. Effect of the TBAB concentration on the reaction of CMG $(0.4 \mathrm{mmol})$ with BPGE $(0.4 \mathrm{mmol})$ in toluene- $d_{8}(0.4 \mathrm{ml})$ at $90^{\circ} \mathrm{C}$ : (A) $2 \mathrm{~mol} \%$; (O) $5 \mathrm{~mol} \%$; (O) $8 \mathrm{~mol} \%$.

chlorogermane with bisepoxide.

Correlation of the degree of conversion of BPGE and the $M_{n}$ of the resulting polymer 4 in the reaction of $\mathrm{CMG}$ with $\mathrm{BPGE}$ using $5 \mathrm{~mol} \%$ of $\mathrm{TBAB}$ as the catalyst at $90^{\circ} \mathrm{C}$ was attempted using the data of ${ }^{1} \mathrm{H}$ NMR spectrum. As shown in Figure 8, the $M_{n}$ of polymer 4 increased dramatically at the final stage of the reaction. This result is a typical example of the stepwise polymerization. 


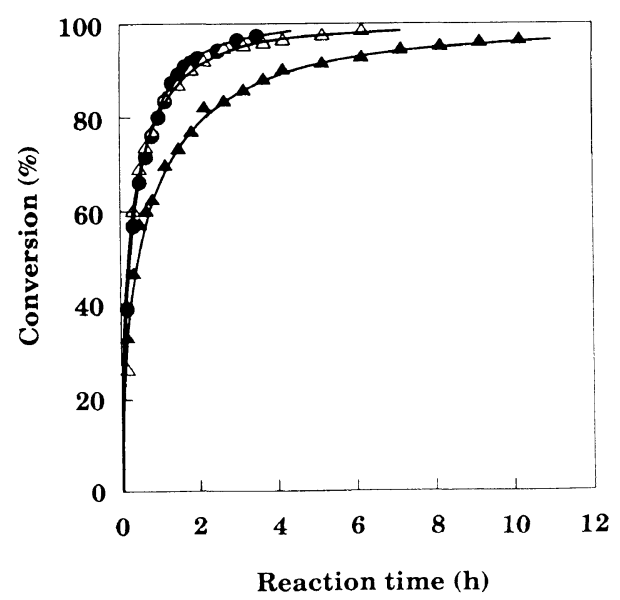

Figure 10. Effect of the monomer concentration on the reaction of CMG $(0.4 \mathrm{mmol})$ with BPGE $(0.4 \mathrm{mmol})$ in toluene- $d_{8}$ using TBAB $(0.04 \mathrm{mmol})$ at $90^{\circ} \mathrm{C}$ : $0.5 \mathrm{moll}^{-1} ;(\triangle) 1 \mathrm{moll}^{-1} ;(\bigcirc) 2 \mathrm{moll}^{-1}$.

The effect of the catalyst concentration on the polyaddition of CMG with BPGE in the presence of TBAB in toluene- $d_{8}$ under the same conditions was examined. As shown in Figure 9 , the rate increased with catalyst concentration; however, the rate with $8 \mathrm{~mol} \%$ of TBAB was nearly the same as the rate with $5 \mathrm{~mol} \%$ of TBAB. Therefore, it seems that $5 \mathrm{~mol} \%$ is a sufficient catalyst concentration for the polyaddition of CMG with BPGE to obtain polymer 4.

As shown in Figure 10, when the reaction was performed with $5 \mathrm{~mol} \%$ of TBAB as the catalyst in toluene- $d_{8}$ at $90^{\circ} \mathrm{C}$, the rate of the addition reaction of CMG with $\mathrm{BPGE}$ was also affected by the monomer concentration, with the rate increasing with the monomer concentration.

Acknowledgments. This work was sup- ported by a Grant-in-Aid for Scientific Research (No. 05650907) from the Ministry of Education, Science, and Culture of Japan, which is gratefully acknowledged.

\section{REFERENCES}

1. C. G. Pitt, M. M. Bursey, and P. F. Rogertson, J. Am. Chem. Soc., 92, 519 (1970).

2. a) R. D. Miller and R. Sooriyakumaran, J. Polym. Sci. Polym. Chem., 25, 111 (1987).

b) J. C. Baumert, G. C. Bjorklund, D. H. Jundt, M. C. Jurich, H. Looser, R. D. Miller, J. Rabolt, R. Sooriyakumaran, J. D. Swalen, and R. J. Twieg, Appl. Phys. Lett., 53, 1147 (1988).

c) V. M. Hallmark, C. G. Zimba, R. Sooriyakumaran, R. D. Miller, and J. F. Rabolt, Macromolecules, 23, 2346 (1990).

3. M. Abkowitz and M. Stolka, J. Non-Cryst. Solid., 114, 342 (1989).

4. a) M. Okano and K. Mochida, Chem. Lett., 701 (1990).

b) K. Mochida, H. Chiba, and M. Okano, Chem. Lett., 109 (1991).

5. a) C. E. Carraher, Jr. and R. L. Dammeier, Makromol. Chem., 141, 245 (1971).

b) C. E. Carraher, Jr., Inorg. Macromol. Rev., 1, 271 (1972).

6. P. Trefonas and R. West, J. Polym. Sci., Polym. Chem. Ed., 23, 2099 (1985).

7. T. Hayashi, Y. Uchimaru, N. P. Reddy, and M. Tanaka, Chem. Lett., 647 (1992).

8. S. Q. Zhou, W. P. Weber, P. Mazerolles, and C. Laurent, Polym. Bull., 23, 583 (1990).

9. a) S. Kobayashi, S. Iwata, M. Abe, and S. Shoda, $J$. Am. Chem. Soc., 112, 1625 (1990).

b) S. Kobayashi, Makromol. Chem. Symp., 47, 393 (1991).

c) S. Kobayashi, S. Iwata, K. Yajima, K. Yagi, and

S. Shoda, J. Am. Chem. Soc., 114, 4929 (1992).

d) S. Kobayashi and S. Cao, Chem. Lett., 25(1993).

10. A. Kameyama, S. Watanabe, E. Kobayashi, and T. Nishikubo, Macromolecules, 25, 2307 (1992).

11. T. Nishikubo, A. Kameyama, and N. Hayashi, Polym. J., 25, 1003 (1993). 